\title{
El voluntariado: entre la ciudadanía y la ideología
}

\author{
Luís Barreiro Carballal \\ Universidad de Santiago de Compostela, España
}

\section{El voluntariado: entre la ciudadanía y la ideología}

Resumen: La razón de ser de este trabajo no es otra que la de estudiar la aparición de una serie de nuevos sujetos políticos en el seno de nuestra sociedad democrática de cambio de milenio, sujetos políticos que o autor considera de entidad suficiente dentro del ámbito del Derecho Constitucional. La Ley estatal 6/1996 del voluntariado, la pléyade de leyes autonómicas de voluntariado y por último, la Ley Orgánica reguladora del Derecho de Asociación de 7 de marzo de 2002, son muestra manifiesta del reciente pero intenso interés por parte de la administración de colonizar este territorio hasta hace poco ignoto. En España ha sido curioso observar cómo el debate sobre la participación política ha ido cambiando de protagonistas. En los años setenta, sólo los partidos y sindicatos podían transformar la sociedad. En los años ochenta, eran los nuevos movimientos sociales los únicos capaces de corregir el capitalismo salvaje. Desde los años noventa exclusivamente el voluntariado es capaz de aportar un mínimo de esperanza a la gris participación social y política.

Palabras claves: voluntariado, participación, sociedad civil, ciudadania.

\section{O voluntariado, entre a cidadania e a ideologia}

Resumo: Este trabalho tem por objetivo estudar o aparecimento de uma série de novos sujeitos políticos na sociedade democrática do câmbio do milênio, sujeitos políticos que o autor considera de importância suficiente no âmbito do Direito Constitucional. A Lei Nacional 6/1996 do voluntariado, a plêiade de leis autonômicas do voluntariado e, por último, a Lei Orgânica reguladora do Direito de Associação de 7 de março de 2002, são amostras manifestas do recente e intenso interesse, por parte da administração, de colonizar este território ignorado até pouco tempo atrás. $\mathrm{Na}$ Espanha, tem sido curioso observar como o debate sobre participação política vem mudando de protagonistas. Nos anos 1970, apenas os partidos e sindicatos podiam transformar a sociedade. Nos anos 1980, os novos movimentos sociais eram os únicos capazes de corrigir o capitalismo selvagem. Desde os anos 1990, exclusivamente o voluntariado é capaz de proporcionar um mínimo de esperança à cinzenta participação social e política.

Palavras-chave: voluntariado, participação, sociedade civil, cidadania.

\section{Voluntary Work, between Citizenship and Ideology}

Abstract: The purpose of this study is to analyze the appearance of a series of new political subjects in democratic society at the change of the millennium, political subjects that the author considers of substantial importance in the realm of Constitutional Law. These include National Law 6/1996 concerning voluntary work, the variety of laws concerning voluntary work and finally the Organic Law, which regulates the Right to Association of March 7 2002. These are all clear examples of the recent and intense interest by the part of the administration in colonizing this until recently ignored territory. In Spain, it has been curious to note how the protagonists have changed in the debate about political participation. In the 1970s, it was seen that only parties and unions could transform society. In the 1980 s, the new social movements were the only voices capable of correcting savage capitalism. Since the 1990s, only volunteers are understood to be capable of offering a bit of hope to the cloudy realm of social and political participation.

Key words: volunteer work, participation, civil society, citizenship. 


\section{Introducción}

\section{El cambio es lo único inmutable en el mundo.} Heráclito de Éfeso

El voluntariado surge en un determinado momento histórico, como consecuencia de lo que podríamos denominar una revolución en los modos de vida: la aparición de una franja de tiempo de ocio para los ciudadanos. Podemos recordar a Keynes (apud GARCÍA ROCA, 2008, online) cuando anunciaba hace ya 70 años que "por primera vez desde la creación del hombre, éste se enfrentará con su problema real y permanente: saber emplear adecuadamente el hecho de verse liberado de sus necesidades económicas más urgentes; ocupar, en suma, su ocio para vivir de forma agradable y sabia".

El surgimiento del llamado Estado de Bienestar fue consecuencia de los efectos de la Segunda Guerra Mundial en Europa. El cúmulo de necesidades de la sociedad de posguerra obligó al Estado a asumir su responsabilidad, generando un pacto social entre los enfermos y los sanos, los parados y los trabajadores, los jóvenes y los ancianos, pacto que requiere la confianza por parte de las generaciones presentes en su mantenimiento por parte de las generaciones futuras. Es, precisamente, la desconfianza actual en la solidez de este pacto la que está generando su crisis que, en paralelo, consolida el corporativismo de las sociedades occidentales. Es en este punto donde podemos vincular voluntariado y Estado de Bienestar, como aporte de legitimación social a la solidaridad institucional.

No nos encontramos ante un concepto pacífico; al contrario, los diversos sistemas ideológicos adoptan posiciones sumamente dispares ante el fenómeno del voluntariado. Ello tendrá evidentes consecuencias en las elaboraciones legislativas fruto de cada sistema, por lo que los distintos modelos de Estado que conviven en nuestra realidad política presentan muy diversos posicionamientos frente al fenómeno del voluntariado. Siguiendo a García Roca (2001, p. 26-39), podemos distinguir entre los siguientes modelos de Estado de Bienestar en relación con el voluntariado.

\section{Modelo conservador de Estado de Bienestar y voluntariado}

La propuesta conservadora consiste en restaurar el orden natural de la comunidad para que su dinamismo resuelva las necesidades sociales. Son las instituciones primarias más próximas al individuo a quienes corresponde proporcionar cada vez más servicios básicos a la ciudadanía. De hecho, los protagonistas del desarrollo social para el modelo conser- vador son la familia, las instituciones religiosas y el conjunto de las organizaciones solidarias. Para que éstas cobren todo su relieve, es necesario que el Estado se retire permitiendo que una parte importante de bienes y servicios se produzcan y distribuyan fuera de él. Esta visión de un voluntariado conservador tiene profundas raíces en el sistema político norteamericano. La pretensión es que el voluntariado vuelva a ser la espina dorsal del espíritu democrático:

El futuro de América es el estudiante que, después de las horas de clase, da clases particulares a un compañero; el líder vecinal que consigue dinero para construir una guardería para niños desfavorecidos; el hombre de negocios que paga la beca a los estudiantes graduados; el voluntario que entrega alimentos en la casa de los ancianos [...] (RYFKIN, 1996, p. 293).

Es esta opción conservadora la que aporta una explicación clave al proceso de institucionalización del voluntariado a lo largo de la década de los noventa, que es cuando en España y en el resto de Europa se elaboran las normativas específicas al respecto, coincidiendo con la realización de los mayores esfuerzos a la hora de buscar soluciones ante "el desmoronamiento de las estructuras económicas y asistenciales del llamado Estado de Bienestar" (MADRID, 1996, p. 79-81). Frente a un periodo en el que las sociedades occidentales han ido avanzando en la construcción y el desarrollo del Estado de Bienestar, las estrategias se invierten y las políticas dominantes que se presentan como vías de salida de la crisis aparecen presididas por el principio de que ha existido un exceso de democracia que es preciso corregir. La llamada sociedad civil es la destinada a solventar este exceso compensándolo con una mayor presencia del mercado.

Es posible diferenciar dentro del citado modelo conservador el que cabe denominar "modelo democristiano". Éste parte, igualmente, del intento de restaurar el llamado orden natural de la comunidad, que determina la recuperación de las dinámicas comunitarias en la resolución de los conflictos sociales. Pretendería convertir el Estado de Bienestar en una Sociedad de Bienestar, pero no transformando a las Administraciones Públicas en un Estado de mínimos, sino reivindicando el ejercicio de los principios de subsidiariedad, corresponsabilidad y complementariedad entre el Estado y la sociedad civil. Se trataría de reducir el monopolio del Estado en el diseño de las políticas de bienestar (Estado de Bienestar) a favor de una mayor participación $y$, en consecuencia, también mayor protagonismo de la sociedad civil, tanto en su diseño como en su ejecución (Sociedad del Bienestar). Lo contrario significaría dar entrada a un modelo libe- 
ral en el que los voluntarios servirían de coartada para desmantelar los sistemas de protección, reduciendo las estructuras estatales e, incluso, apuntan algunos, "desinventándolo". En palabras del ex presidente del gobierno de España José María Aznar López:

[...] surgen dos concepciones: la de quienes siguen propugnando el Estado de Bienestar, como en el Programa 2000 del PSOE, y la de quienes propugnamos la teoría de la Sociedad del Bienestar. Es decir, frente al 'Estado de gastos', que decía Schumpeter, el Estado con limitaciones, precisamente para garantizar su fortaleza y eficacia, en una sociedad cada vez más libre. Tenemos que ser muy claros: el Estado de Bienestar se ha hundido solo. Se ha hundido solo porque ha querido ser Estado con la máxima competencia, válido para un momento determinado de la Historia, pero difícilmente aplicable ahora. Y se ha hundido solo porque practica el dirigismo como norma de conducta frente al Estado liberal, que respeta y favorece la creatividad individual y la espontaneidad social (AZNAR LÓPEZ, 1991.p. 27).

Es frecuente encontrar opiniones que detectan una derivación del Estado de Bienestar de tipo socialdemócrata al Estado de bienestar democristiano, en ocasiones confundido con el liberal, al producirse un trasvase de transferencias de fondos sociales destinados a políticas universales, a acciones asistenciales, al otorgarse un mayor protagonismo al sector privado en la financiación y en la gestión de las transferencias sociales y, finalmente, al concederse un mayor peso a la familia como centro de imputación de responsabilidades sociales colectivas y, a la vez, como perceptor elemental de transferencias. Lo cierto es que, pese a la influencia de estos planteamientos en cuanto a la motivación de las esferas públicas para fomentar el trabajo voluntario en los ámbitos sociales, este modelo es extraño, en el caso español, a la práctica legislativa tanto estatal como autonómica. Es más, en palabras de Iglesias-Redondo (2001, p. 24), semejante opción se rechaza expresamente, en virtud del consenso inherente a la aceptación de los presupuestos político-económicos hegemónicos en la cultura occidental.

\section{Modelo liberal de Estado de Bienestar y voluntariado}

En la doctrina liberal era la familia el agente de protección social preferente y casi exclusivo. La primitiva dogmática liberal se oponía rigurosamente a todo intervencionismo protector, ya fuera por agentes públicos (beneficencia, leyes sociales) o por agentes privados (filantropía, asociacionismo). Unos y otros perturbarían el buen orden que cabe esperar del libre juego de los intereses individuales. Con el paso del tiempo, el liberalismo (ya denominado neoliberalismo) moderó tales posiciones, llegando a participar en la construcción consensuada del Estado de Bienestar ${ }^{1}$. No obstante, lo contempla con desconfianza pues se le atribuye una limitación en la libertad del ciudadano y en los estímulos para el desarrollo de sus actividades: los efectos redistributivos del Estado de Bienestar merman la capacidad de ahorro de la clase empresarial, reduciendo así su potencial de generar empleo. La creación de instituciones y normas para proteger al trabajador o al medio ambiente impacta negativamente sobre la eficacia económica. El ideal político neoliberal consiste en reducir el Estado interventor.

En el ámbito de las políticas sociales, el Estado reducirá su ayuda a los que se compruebe que no tienen medios, limitará con efectividad el alcance de los derechos sociales, estimulará el mercado "bien pasivamente - garantizando solo un mínimo - o activamente, dando subsidios a planes privados de protección social" (ESPING-ANDERSEN, 1993, p. 47). Justo es reconocer que el movimiento asociativo no acepta de buen grado esta "retirada" estatal; al contrario, recuerda "al Estado sus obligaciones haciendo visible que el voluntariado no sustituye ninguna responsabilidad del mismo Estado" (PLATAFORMA..., 2000, II. f.).

El voluntariado sirve, así, de excusa para desmantelar los sistemas de protección, ya que se atribuye a los voluntarios una mejor satisfacción de las demandas de los ciudadanos, atribución que, en ocasiones, se deja entrever en los debates en sede parlamentaria: la ley de voluntariado "contribuye a desburocratizar y a flexibilizar las acciones, adaptándose a los medios y acercando, además, los servicios a los ciudadanos [...] muchas veces se llega hasta lugares en donde el Estado con su acción sería imposible que pudiera acercarse"2.

Al mismo tiempo, se espera de él que amortigüe los efectos de la desigualdad social. El voluntariado funciona, de esta manera, como una ampliación de las actividades de los actores del mercado, viéndose sometido a los criterios de organización económica y empresarial. La vinculación entre empresas y organizaciones de voluntariado, incluso a efectos publicitarios, responde a este modelo, que probablemente sea el hegemónico en las sociedades occidentales. En ellas se está configurando un auténtico mercado de la solidaridad, acrítico y profundamente enraizado en el sistema de economía de mercado. Sirva de ejemplo que uno de los fines del voluntariado considerados de interés general en la Ley 6/1996 del voluntariado de España es el de la defensa de la economía (artículo 4) ${ }^{3}$. 


\section{Voluntariado y Estado de Bienestar socialdemócrata}

En el contexto socialdemócrata, el voluntariado comienza percibiéndose como una realidad provisional, que tiene su razón de ser sólo mientras el Estado no alcance a completar todas sus funciones ${ }^{4}$. Es el Estado el que está llamado a actuar como máximo agente nivelador de las desigualdades sociales que se generan en las sociedades con economía de mercado. Se trata, desde esta visión estatalista, de un fenómeno inútil, si no contraproducente. En una segunda fase, dadas las dimensiones alcanzadas por el fenómeno, de manera que es imposible ignorarlo, el modelo socialdemócrata se caracterizará por su decisión de sujetar al voluntariado a la Ley y a la política, ya que reconoce que las iniciativas sociales son un elemento que se ha desvelado decisivo para equilibrar el mercado con medidas de solidaridad social. El argumento es que: "En los próximos años, si cabe más, para seguir desarrollando el Estado de bienestar, necesitaremos de esos movimientos voluntarios, para hacer nuevas prestaciones sociales"5. De este modo, el voluntariado se convierte en un instrumento de las políticas públicas de las Administraciones, que a cambio de la concesión de subvenciones, esperan la aceptación por parte de las organizaciones del Tercer Sector de su carácter instrumental (GARCÍA ROCA, 2001, p. 33).

Son los partidos políticos quienes poseen la exclusividad en la organización democrática, mientras que el voluntariado pertenece a la esfera privada de los intereses y demandas particulares ${ }^{6}$. El ejercicio de responsabilidades públicas se considera la vía privilegiada de transformación social. Es, por ello, que la socialdemocracia nunca ha priorizado el desarrollo de un espacio público autónomo ni de un protagonismo social del voluntariado que no fuera el de servir exclusivamente de puente para el trasvase de los voluntarios al trabajo de partido, el único trascendente. Casado (1989, p. 219), de forma muy descriptiva, compara al excluyente modelo socialdemócrata con la exclamación ¡dejadme sólo! de los toreros, reclamando su sustitución por una fórmula pluralista y de colaboración.

Mención aparte merecerían las denominadas "terceras vías", surgidas desde el interior de la socialdemocracia europea, sobre todo, a partir de las reflexiones de Giddens para resituar a la sociedad civil en un nuevo equilibrio con el Es- tado. Son legión los testimonios que incorporan el voluntariado al discurso político de esta opción reformista. De entre todos, extraemos uno de que fue líder laborista y primer ministro británico Tony Blair:

Los gobiernos no deben dar al traste con la valiosa actividad de los colectivos locales y del voluntariado. El lastimoso error de la izquierda fundamentalista del siglo XX fue creer que el Estado podía reemplazar a la sociedad civil y, en consecuencia, impulsar la libertad. La nueva derecha cae en el otro extremo, defendiendo el desmantelamiento total de la actividad del Estado en nombre de la libertad. [...] Un reto clave que se plantea a toda política progresista es el uso del Estado como fuerza habilitadora, protegiendo a las colectividades y al voluntariado, y fomentando su crecimiento para satisfacer nuevas necesidades, en colaboración cuando sea necesario (BLAIR, 1998, p. 66-67).

Estamos ya muy lejos del paradigma socialdemócrata tradicional y muy cerca de las propuestas de la denominada nueva izquierda.

En el caso español, el alcance de este modelo ha superado los límites ideológicos en que se originó y, en la actualidad, la generalidad de las Administraciones, con independencia del color político de cada gobierno, parten de principios que responden en buena medida a los presupuestos socialdemócratas, en su versión más marcadamente estatalista.

\section{Estado de Bienestar y nueva izquierda}

Frente a la pretensión neoliberal de reducir el Estado, y la socialdemócrata de expandirlo, la nueva izquierda sostiene que lo necesario es reconstruirlo. Contrariamente al papel exclusivo que la izquierda clásica concedía al Estado, ahora se afirma que éste no puede ni debe hacerlo todo, de tal forma que se recuperan los diversos actores sociales, y se responde, así, a las demandas de participación de la sociedad. Mientras que los liberales adelgazan al Estado a causa de su crisis fiscal, la nueva izquierda lo reduce, como efecto del desarrollo de los vínculos sociales y de la solidaridad. Manifestación de esta nueva orientación política son los partidos verdes ${ }^{7}$, en la que los denominados Nue- 
vos movimientos sociales y, en general, el Tercer Sector han tenido una importancia radical.

Caillé describe cuál es la visión de la nueva izquierda respecto al papel del Estado en el fomento del voluntariado, sin ocultar sus reticencias ante la falta de control real sobre las organizaciones:

El Estado debe invertir masivamente en el Tercer Sector y apostar por la dinámica asociativa, reforzando a la vez la vigilancia fiscal y contable, especialmente sobre las grandes asociaciones, que cada vez se parecen más a máquinas de blanquear dinero de procedencia dudosa. A muy corto plazo, hay varias medidas concebibles y necesarias: instituir un estatuto del voluntariado, que dé derecho a Seguridad Social y jubilación; favorecer financieramente el compromiso con el voluntariado otorgándole créditos fiscales [...]. Pero lo esencial, si verdaderamente se quiere desarrollar la autonomía asociativa y hacer de las asociaciones los representantes legítimos de la sociedad viva y real, reside en asegurarles mayores y más regulares posibilidades de financiación, favoreciendo las donaciones en su favor. ¿Por qué no autorizar al contribuyente a que destine libremente el $5 \%$ de su impuesto sobre la renta a las asociaciones reconocidas que prefiera, estableciendo a cambio un mayor control sobre las asociaciones beneficiarias?(CAILLÉ, 1997, p. 16).

No obstante, la relación entre voluntariado y nueva izquierda no siempre resulta pacífica: la pretensión del primero de superar los actuales niveles de protección de los colectivos más desfavorecidos puede llegar a cuestionar los vigentes estándares de bienestar del conjunto de la población. De esta forma, se hace necesario desestabilizar el actual Estado de Bienestar para ir más adelante. Así, Glotz (1987, p. 310) declara, con absoluta nitidez, que

La izquierda debe poner en pie una coalición que apele a la solidaridad del mayor número posible de fuertes con los débiles, en contra de sus propios intereses; para los materialistas estrictos, que consideran que la eficacia de los intereses es mayor que la de los ideales, ésta puede parecer una misión paradójica, pero es la misión que hay que realizar en el presente.

\section{Conclusiones}

Para la consecución de tal logro parece imprescindible buscar solución "al malestar social con los partidos" que "no puede venir de la reforma interna de estos, sino que tiene que pasar por el 'desapoderamiento' de los partidos y la progresiva recuperación por parte de la sociedad de alguna de las tareas que se habían delegado en ellos" (BLANCO VALDÉS, 1996, p. 191).

Parte de estas funciones pueden y deben ser asumidas por entidades de iniciativa social, organizaciones que no tengan como objetivo el logro de poder politico y como medio la lucha partidista. No obstante debemos recalcar que recuperar para la sociedad parte del territorio cedido a la clase politica no significa privatizar, sino socializar. Para ello sería deseable que la administración profundizase en los mecanismos que garanticen la transparencia de las organizacións no lucrativas: redención de cuentas, auditorias, establecemiento de incompatibilidades en los miembros de las juntas directivas o patronatos, etc.

Atendiendo a estas propuestas de reforma social y política se evidencia el relevante papel reservado al fenómeno voluntario en la nueva configuración de nuestras sociedades. Esta relevancia es también cuantitativa, y requiere el adecuado tratamiento legislativo, además de un reconocimiento institucional que no siempre se ha producido.

\section{Referencias}

AZNAR LÓPEZ, J. M. Libertad y solidaridad. Planeta: Barcelona, 1991.

BLAIR, T. La tercera vía. Madrid: El País-Aguilar, 1998.

BLANCO VALDÉS, R. L. Ley de Bronce, partidos de hojalata (crisis de los partidos y legitimidad democrática en la frontera del fin de siglo). In: PORRAS NADALES, A. J. El debate sobre la crisis de la representación política. Madrid: Tecnos, 1996. p. 191-230.

CAILLÉ, A. Treinta tesis para una nueva izquierda. Comment peut-on être anticapitaliste? MAUSS, Paris, n. 9. Primer sem. 1997. Versión en castellano publicada en Iniciativa Socialista, n. 47, dic. 1997.

CASADO, D. Organizaciones voluntarias y calidad de vida. In: SIMPOSIO SOCIEDAD CIVIL E INSTITUCIONES DEMOCRÁTICAS. Palma de Mallorca, 1989. Madrid: Editorial Popular, 1989.

ESPING-ANDERSEN, G. Los tres mundos del Estado de Bienestar. Valencia: Edicións Alfons El Magnànim, 1993.

GARCÍA ROCA, J. Voluntários y cristianos. 5 sept. 2008. Disponible en: <http://voluntariadoconsolacion. blogspot.com/2008/09/voluntarios-y-cristianos.html>. Aceso en: jan. 2009.

El voluntariado en la sociedad del bienestar. Documentación Social, Madrid, n. 122, enero-marzo 2001. 
GLOTZ, P. Manifiesto para una nueva izquierda europea. Madrid: Siglo XXI, 1987.

IGLESIAS REDONDO, J. I. Algunas reflexiones sobre la Ley $3 / 2000$, de 22 de diciembre, del voluntariado de Galicia. In: MILLÁN CALENTI, J. (Comp.). Voluntariado social. Santiago de Compostela: Instituto Gallego de Iniciativas Sociales y Sanitarias, 2001.

MADRID, A. Acerca de la ley del voluntariado. En Pie de Paz, Madrid, n. 40, p. 79-81, 1996.

PLATAFORMA PARA LA PROMOCIÓN DEL VOLUNTARIADO EN ESPAÑA. Código ético de las organizaciones de voluntariado. Madrid, 18 nov. 2000.

RIFKIN, J. El fin del trabajo. Barcelona: Paidós, 1996.

RUIZ OLABUÉNAGA, J. I. (Dir.). El sector no lucrativo en España. Bilbao: Fundación BBV, 2000.

\section{Notas}

1 Basta recordar que el legendario Lord Beveridge era liberal (CASADO, 1989,p. 110).

2 Intervención de la ponente del Grupo Popular Sainz García en el pleno de aprobación de la ley del voluntariado. Diario de Sesiones del Congreso de los Diputados, de 27 de diciembre de 1995,n. 195.p. 10334.

3 Disponible en: $<$ http://www.iniciativasocial.net/ley1.htm $>$.

4 O labuénaga recoge las poco afortunadas declaraciones del que denomina "cierto líder político-profesional muy significado en el PSOE" que, en referencia a la reforma de los servicios sociales, abrió su charla en un seminario sobre planificación social aproximadamente con estas palabras: "Acabo de tener una reunión con representantes de Cáritas, Cruz Roja y otras organizaciones privadas para explicarles el plan que estamos elaborando. Mediante el cual ya no será necesaria su actuación" (RUIZ OLABUÉNAGA, 2000, p. 232).

5 Intervención de la representante del Grupo Parlamentario Socialista en el pleno de aprobación de la ley del voluntariado. Diario de Sesiones del Congreso de los Diputados, de 27 de diciembre de 1995, n. 195.p. 10334.

6 Ejemplo de esta posición es la enmienda a la totalidad (n. 15147) formulada por el Bloque Nacionalista Galego al proyecto de ley del voluntariado de Galicia: "Resalta la desconfianza en un tiempo en que los ataques al Estado de bienestar son constantes desde las fuerzas representativas de la derecha política. Ejemplos tenemos de las consecuencias de sustituir aspectos de justicia social que le corresponden al Estado, social, democrático y de derecho, por actividades de solidaridad voluntaria que no tienen por que tener la misma eficacia ni plenas garantías para los ciudadanos y ciudadanas"(Boletín Oficial do Parlamento de Galicia, número 571, 7 de septiembre de2000, p. 23998).

7 Muy significativamente, el Partido Verde alemán.

\section{Luís Barreiro Carballal}

luis.barreiro@edu.xunta.es

Profesor de Fundamentos del Derecho para el Trabajo Social, Universidad de Santiago de Compostela Profesor de Derecho Constitucional, Universidad de a Coruña

Presidente del Instituto Galego para a Xestión do Terceiro Sector (Igaxés-3)

\author{
Universidad de Santiago de Compostela \\ Escuela Universitaria de Trabajo Social \\ San Martiño Pinario \\ Praza da Inmaculada, 5, $2^{\circ}$ \\ 15704 \\ Santiago de Compostela - España
}

